\title{
Sand grains versus tiny glass granules - comparative study on stress-deformation characteristics
}

\author{
Danuta Leśniewska ${ }^{1, *}$, Iwona Radosz $^{2}$, and Magdalena Pietrzak $^{2}$ \\ ${ }^{1}$ Polish Academy of Sciences, Institute of Hydro-Engineering, Gdańsk, Poland \\ ${ }^{2}$ Koszalin University of Technology, Civil Engineering Department, Koszalin, Poland
}

\begin{abstract}
Glass granules and grains of crushed glass usually replace sand if photo-elastic observation of load-transmitting 'force chains' is planned. Still an open question exists however, how well glass granules can represent real sand grains. This paper in its first part compares simple uniaxial crushing tests on glass grains (both granules and crushed glass) and on coarse sand grains (micro-scale). Some basic geometrical characteristics of glass and sand grains are discussed, then the measurement techniques are presented and the results of crushing tests demonstrated. The second part of the paper contains the results of 'macro-scale' loading tests on big granular samples, made of $\sim 10^{6}$ glass or sand grains. The deformation characteristics of these samples differ significantly.
\end{abstract}

\section{Introduction}

Glass granules and grains of crushed glass usually replace sand if photo-elastic observation of loadtransmitting 'force chains' is planned. Application of glass particles to model sand behaviour seems to be, as far, the only way of recording experimental 'force chains' by photographic technique. The first images of 'force chains' were reported already in 1950-ties by Dantu and Wakabayashi [1,2] and later in several classic papers by Drescher, De Josselin de Jong, Dyer, Allersma and others [3-5].

Recently the use of photo-elastic observation of granular materials has gained some important new tools, which enable more systematic research by means of digital photography and image analysis, supported by PIV or DIC methods. Still an open question exists however, how well glass granules can represent real sand grains. It is especially important in view of modern trend to relate grain-scale and macro-scale features of granular materials. Also a broad application of DEM to simulate numerically the structure of 'force chains' makes the problem important - some kind of 'physical calibration' is necessary to validate numerical results.

This paper compares simple uniaxial crushing tests on glass grains (both granules and crushed glass) and on corresponding (by similar $\mathrm{d}_{50}$ ) coarse sand grains. First some basic geometrical characteristics of glass and sand grains are briefly discussed, then the measurement technique is presented and the results of crushing tests demonstrated (including the averaged stress-deformation relationships).

Some glass grains were tested when placed inside circular polariscope, to investigate their residual ability to bear external loading.
The second part of the paper contains the results of uniaxial loading tests on big granular samples, made of $\sim 10^{6}$ glass or sand grains.

\section{Materials tested}

\subsection{Glass granules}

Transparent glass beads Starlitbeads $1000\left(\mathrm{~d}_{50} \sim 1.1 \mathrm{~mm}\right)$ were selected in previous research as a substitute of coarse sand grains to fulfil the demands of integrated photo-elasticity [4, 5]. Fig.1 shows the selection of glass granules representing their most coarse fraction (grain diameter bigger than $1.4 \mathrm{~mm}$ ) enlarged 50 times.

It can be seen that the granules are not perfectly spherical (with some spread of grain diameters) but of regular convex shape.

Their additional characteristic feature is the fact that raw granules, as supplied, possess some initial stresses due to the rapid cooling - a part of the manufacturing process. This acts as pre-compressing, like in case of other structural materials, and is of great importance in case of photo-elastic testing, as thermal stresses add to the photo-elastic effect, introduced by a grain loading, and make the effect less visible.

To improve the quality of photo-elastic images, glass granules must be thermally tempered by heating up to about $600^{\circ} \mathrm{C}$ and subsequently cooled slowly to room temperature. The initial thermal 'pre-compressing' of glass granules can, at least partly, explain their high crushing strength, reported in Section 4. Fig.2a shows a glass granule in its natural state (neither tempered nor loaded) placed in immersion liquid (clove oil) and photographed in circularly polarized light $[4,5]$.

\footnotetext{
* Corresponding author: danuta.lesniewska@ibwpan.gda.pl
} 


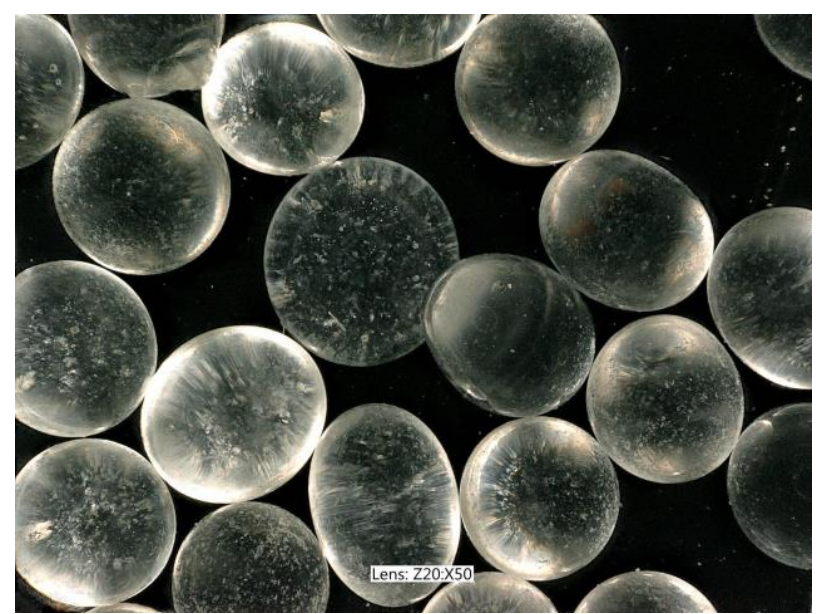

Fig. 1. The coarsest fraction of Starlitbeads 1000 (glass granules), magnified 50 times.

In Fig. $2 b$ the identical grain is shown after tempering. It can be seen that the initial stress is removed and the grain becomes practically invisible (optical transparency is required to register the external stresses imposed on a grain in a clear way). The slightly non-uniform grain image brightness in Fig.2b and c (higher brightness at contact points between the grains and metal clumps of the testing apparatus) is a result of some minimum stress necessary to keep the grain in place before starting the crushing test.

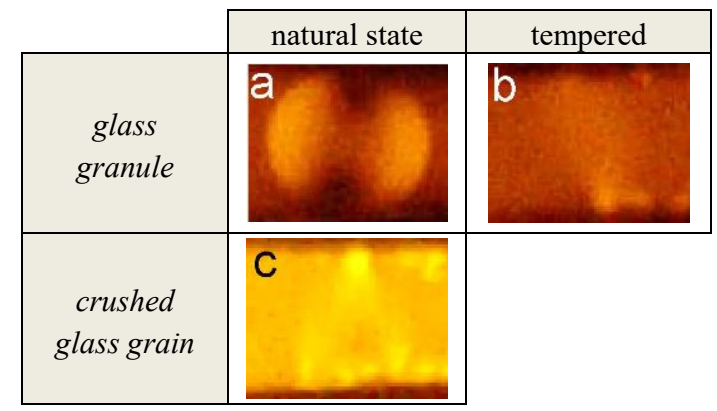

Fig. 2. Images of glass granules taken in circularly polarized light: a - glass granule before tempering (natural state), $\mathbf{b}-$ glass granule after tempering (stress free), $\mathbf{c}$ - grain of crushed glass in its natural, stress free state.

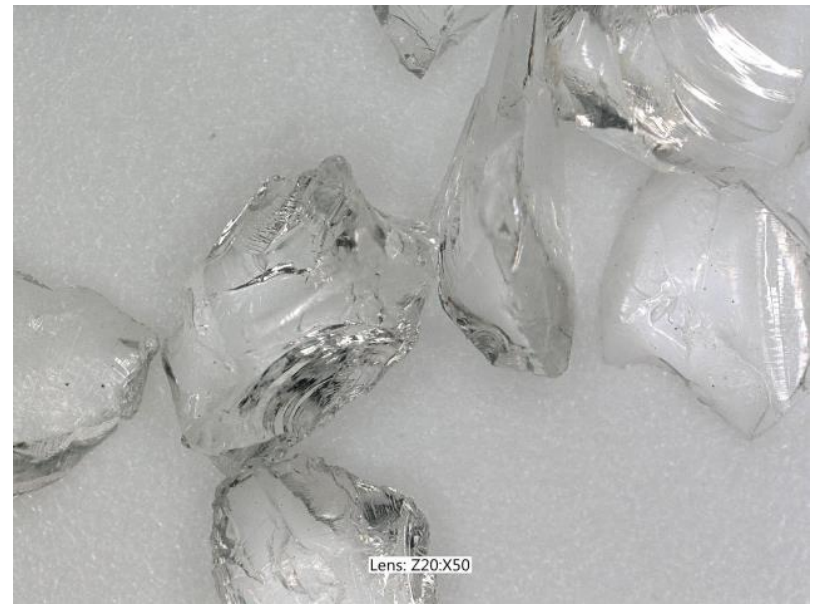

Fig. 3. Crushed glass grains magnified 50 times (Pyrex glass).

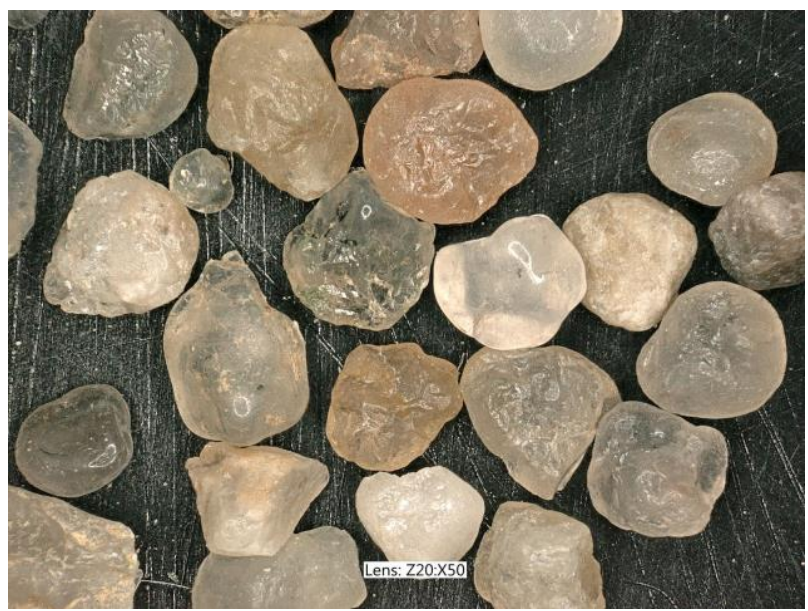

Fig. 4. Grains of quartz sand, magnified 50 times.

\subsection{Crushed glass grains}

Quite different situation exists in case of grains of crushed glass, presented in Fig.3. They were created by crushing Pyrex glass sheet and show extremely irregular shapes and very sharp edges, but no internal initial stresses (Fig.2c). Lack of internal stresses is the obvious result of the crushed glass manufacturing process in glass crushing mills. So using crushed glass in photoelastic experiments allows to avoid tempering, which is time consuming and quite difficult to control in case of small grains.

\subsection{Quartz sand}

A sample of quartz sand grains is presented in Fig.4. Diameter $\mathrm{d}_{50}$ of this sand is the same as in case of glass granules - $1.1 \mathrm{~mm}$. The sand is obviously less monodisperse, its grains have more complex shape, far from spheroidal, and typical grain surface is convex, but with minor concavities. The edges of individual grains are smooth, thus creating bigger grain contact area than in case of crushed glass. If grain shape is taken into account, real sand grains lie in between both surrogate materials (glass granules and crushed glass). It is not possible to use photo-elastic technique for real sand, because sand grains are opaque. Lack of optical transparency is the main reason for using different kinds of artificial grains to study granular materials by photoelastic method.

\section{Experimental techniques}

The results of two different types of tests are presented in the paper: micro-scale test on single grain (grain crushing test) and macro-scale test on granular sample consisting of $\sim 10^{6}$ grains (normal loading). The number of grains in macro-scale tests is typical rather for small scale geotechnical models than real geotechnical structures, but it certainly exceeds what is understood by so called meso-scale, covering only dozens of grains. 


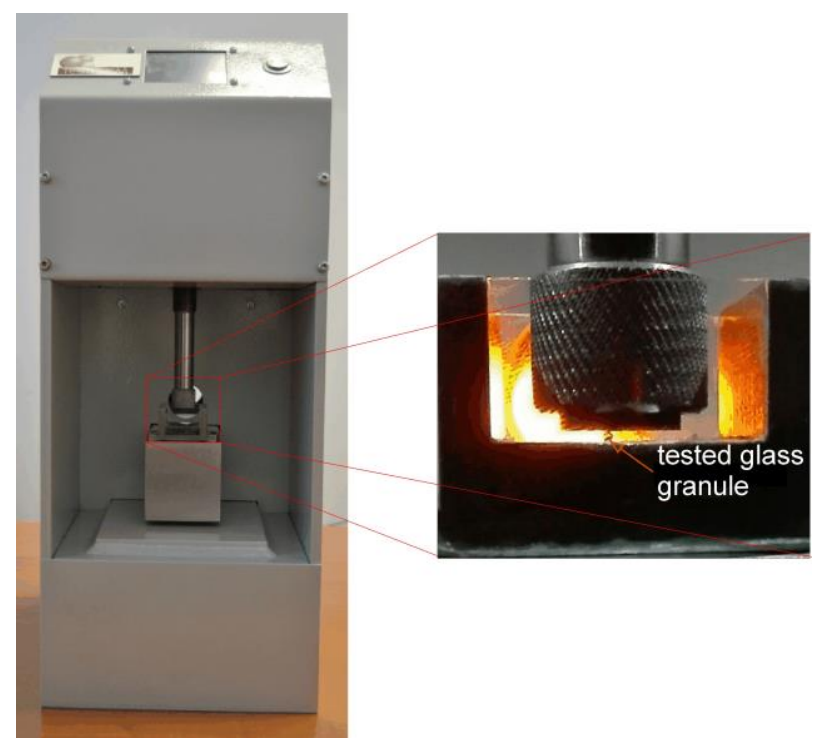

Fig. 5. Mini press for grain crushing.

The purpose of the tests presented here was to study the individual and collective response of different types of grains to the selected range of external load.

Both types of tests were recorded by standard digital camera in ordinary or circularly polarized light $[4,5]$.

\subsection{Grain crushing test}

Grain crushing tests were performed in the mini press presented in Fig.5, equipped in its back with an additional circular hole to enable photo-elastic observation. A series of diametric compression tests on a single-particle was performed to observe typical grain behaviour under uniaxial crushing for all three types of grains (glass granules, crushed glass and quartz sand).

Grains were loaded with low constant speed in a quasi-static manner, until the grain breakage occurred. Load-time (displacement) curves and values of maximum (crushing) force were automatically registered for all the tests and in case of some selected ones the photo-elastic images of loaded grains were taken at constant time intervals. The tests were carried out on 50 selected grains of each type. Grains of a diameter greater than $1.4 \mathrm{~mm}$ were chosen for testing.

Before the loading started, the grains were held in a proper position by a drop of water. In cases where photoelastic equipment was used, grains were immersed in clove oil of refractive index similar to glass, [4].

\subsection{Loading of granular sample}

To study the collective response of different types of grains to the external loading, the experimental setup shown in Fig.6 and used in earlier research [4, 5] was employed, after some simple modifications.

The same technique as before was applied: the experiments have been performed in a glass sided box with dimensions shown in Fig. 6, giving a thickness of the plane strain model of $20 \mathrm{~mm}$.

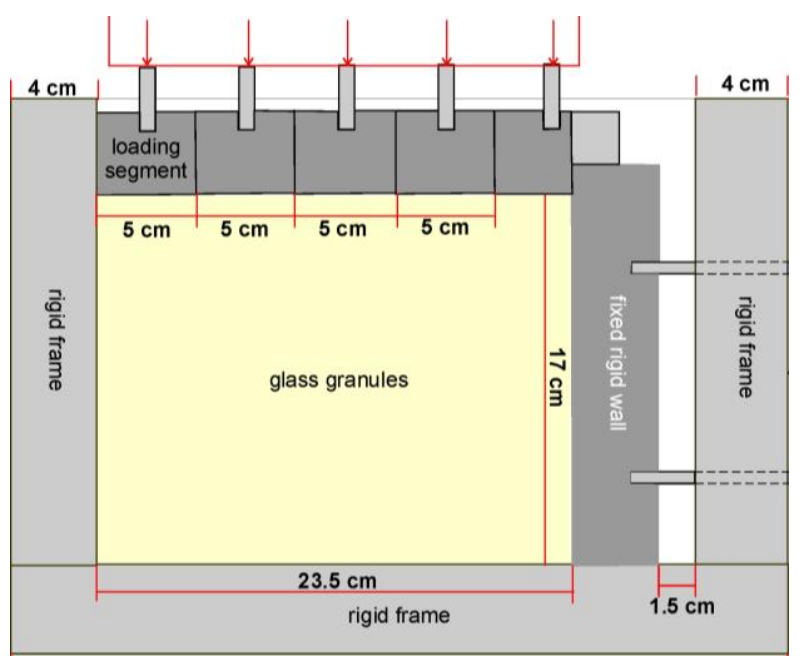

Fig. 6. Test box arrangement for 'macro-scale' tests.

The glass sides of the box are $20 \mathrm{~mm}$ thick and have to sustain the lateral pressures from the granular material.

Rectangular granular samples $(23.5 \mathrm{~cm} \times 17.0 \mathrm{~cm} \mathrm{x}$ $2.0 \mathrm{~cm}$ ) are formed by pouring from hopper which has a length equal to the length of the required sample. The base of the hopper is opened and the grains rain over the entire length of the model. Pouring is stopped when the surface of the layer of grains is near the top of the wall. The surface is then levelled off.

Various loading configurations can be implemented in the box. The particular configuration used here is shown in Fig. 6: a vertical wall some $170 \mathrm{~mm}$ high is fixed to the rigid frame by two rods to unable horizontal movement of the sample - only vertical displacement is allowed. The vertical surface loading is provided by an articulated footing formed of five segments each of which is able to move separately, but which are connected to a common pressure source so that, even if the individual sections of the footing settle, the pressure on each can be maintained.

A loading block is placed on top of the box and fixed to the test tank. This block contains five hydraulic cylinders which can be simultaneously pressurized with a hydraulic pump. The range of pressures which can be applied by the loading system is $0-4.0 \mathrm{MPa}$. Typical tests have consisted of stages of loading in steps of $0.2 \mathrm{MPa}$.

\section{Results and discussion}

\subsection{Grain crushing test}

\subsubsection{Strength of individual grains}

Each grain crushing test was performed in mini-press shown in Fig.5 and continued until a grain was totally damaged.

Mechanisms of grain damage were different for each type of grains investigated. The evolution of crushing force for all the three types of grains is illustrated in Figs. 7 and 8 . 


\section{Grain crushing test:}

blue - glass granules, red - crushed glass grains

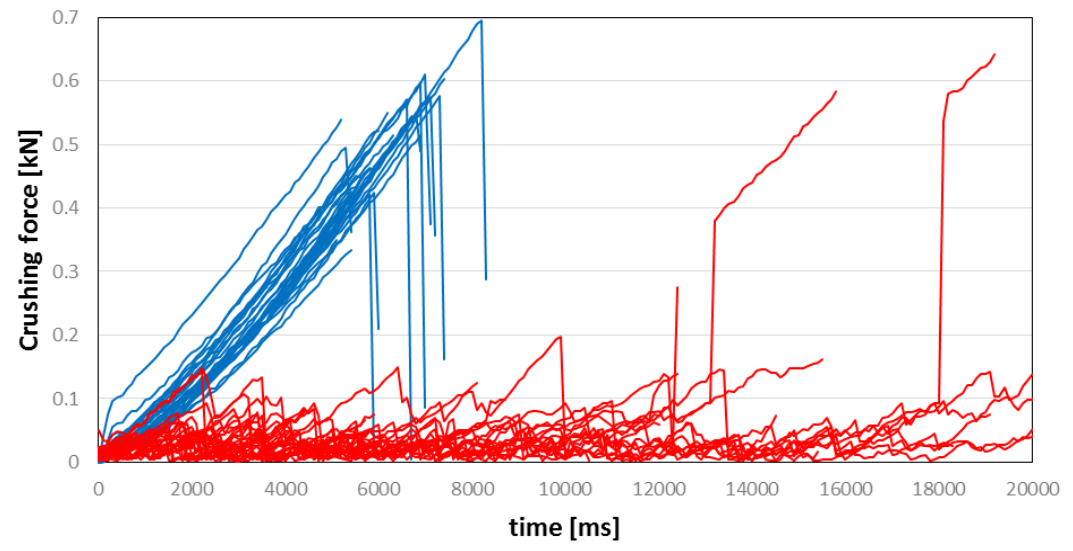

Fig. 7. Results of grain crushing test - value of crushing force versus time: blue - glass granules, red - crushed glass.

Fig.7 presents changes of crushing force for 25 glass granules and 25 crushed glass grains (a number of grains included in the graph is limited for the clarity of the picture). It can be seen that statistically the glass granules damage at much higher force than crushed glass. The change of force with time is monotonic and almost linear. At some moment glass granules suddenly disintegrate and remaining debris are so fine, that they are not able to bear any further load (Fig.8 - top right).

Crushed glass grains demonstrate quite different behaviour - they split into relatively big parts at much lower loading force and each piece preserves some strength. As a result the crushing force changes nonmonotonically and it is difficult to determine the actual moment of grain damage. Such behaviour is typical for grain-scale brittle fracture - phenomenon controlling the compaction behavior of reservoir rocks during the early stages of burial [6].

Fig. 8 confirms the above findings - it shows two subsequent moments of the two crushing tests (first on a glass granule and second on a crushed glass grain), photographed in circularly polarized light.

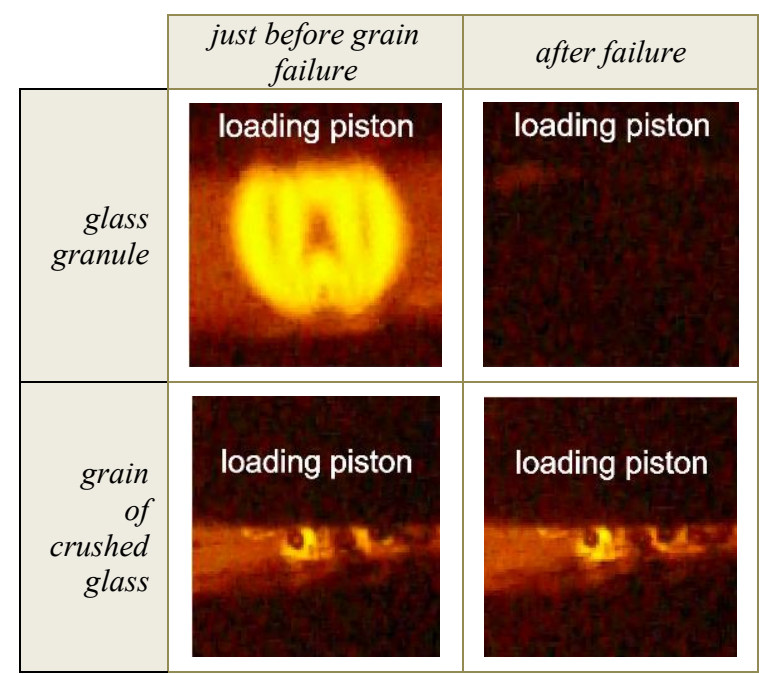

Fig. 8. Photo-elastic image of glass granule and crushed glass grain before and after failure - high image brightness indicates high stress.
The glass granule gains its maximum brighness (the indication of high stress) just before falling apart. The dark picture top right shows that no grain parts preserve any strength after damage.

The crushed glass grain during course of loading also falls apart, but into much bigger pieces, resistant to further damage and able to bear some load, what is proved by their image brightness (Fig.8, bottom).

To examine different grain behaviour more precisely it is necessary to eliminate dependence on grain dimensions. It can be achieved by estimating stress, acting on individual grain. Nine grains were selected for such an analysis - their average dimensions are given in Table 1.

Dimensions of glass granules and sand grains were measured using precise caliper. Such measurement was not possible in case of crushed glass grains due to the local damage of their sharp edges during measurement. Because of that the dimensions of crushed glass grains were estimated on the base of sieve test.

The estimate of stress acting on a grain was made on the base of Table 1 - the values of crushing force were divided by the surface of the circle of diameter equal to the average grain diameter $d_{a v e}$.

\begin{tabular}{|c|c|c|}
\hline \multicolumn{2}{|c|}{$\begin{array}{l}\text { Table 1. Average dimensions } \\
\text { of grains represented in Fig. } 9 \text {. }\end{array}$} & $\begin{array}{c}\text { average } \\
\text { grain diameter }\end{array}$ \\
\hline \multirow{3}{*}{$\begin{array}{c}\text { glass } \\
\text { granules }\end{array}$} & grain 1 & 1.1 \\
\hline & grain 2 & 1.1 \\
\hline & grain 3 & 1.1 \\
\hline \multirow{3}{*}{$\begin{array}{l}\text { coarse } \\
\text { sand }\end{array}$} & grain 1 & 2.4 \\
\hline & grain 2 & 3.2 \\
\hline & grain 3 & 2.8 \\
\hline \multirow{3}{*}{$\begin{array}{l}\text { crushed } \\
\text { glass }\end{array}$} & grain 1 & $1.7^{*}$ \\
\hline & grain 2 & $1.7^{*}$ \\
\hline & grain 3 & $1.7^{*}$ \\
\hline
\end{tabular}

* - in case of crushed glass grains dave determined by sieve.

\footnotetext{
* Corresponding author: danuta.lesniewska@,ibwpan.gda.pl
} 


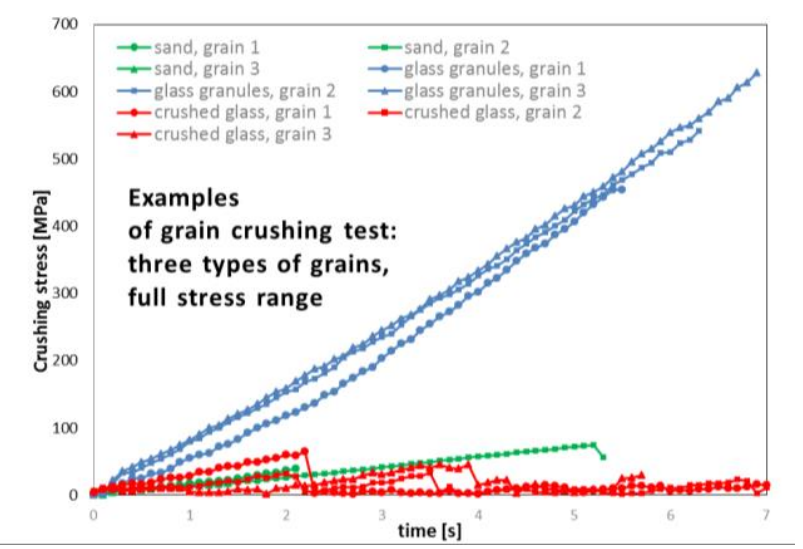

Fig. 9. Results of grain crushing tests performed on 9 selected grains of glass granules, crushed glass and sand for full stress range (from zero to ultimate strength).

Fig.9 presents basic difference in response to external loading between glass granules, sand grains and crushed glass. It can be seen that glass granules exceed the other two types of grains in value of the ultimate strength, which reaches some $700 \mathrm{MPa}$ in comparison to about $70 \mathrm{MPa}$ in case of sand and crushed glass. It could suggest that crushed glass makes better substitute of natural granular materials in photo-elastic tests, if value of ultimate strength of individual grains would decide of deformation characteristics of a granular sample.

As Fig.9 shows, the ultimate strengths of sand and crushed glass grains are very close, but the evolution of stress during loading is significantly different: the stress in case of sand grains increases monotonically to its limit value, while in case of crushed glass it exhibits several parts of linear increase followed by sudden falls and then rise. This mechanism was explained in the previous section. Linear increase of stress with time is common for glass granules and quartz sand grains, however it leads to very different ultimate values, much greater in case of glass granules.

\subsubsection{Practical stress range}

The range of stresses limited by a grain strength, shown in Figs 7 and 9 lies behind the range of stresses common in geotechnical practice or in physical modelling of geotechnical problems. The usual level of external stress applied in photo-elastic testing to ensure distinct photoelastic effect do not exceed 1.0MPa [1-3]. In the previous research reported in [4] and [5] the stress level was unusually high, but did not exceed $4 \mathrm{MPa}$. In view of Fig.9 no grain crushing could be expected for any type of grains under consideration.

In such a case the whole course of the relationships presented in Figs 7 and 9 cannot be helpful in validating the usefulness of artificial grains to substitute natural materials. In fact, only their initial parts can help to explain what may be happening within granular samples. The 'close-up' of Fig.9, limiting the stress range to about $80 \mathrm{MPa}$ is shown in Fig. 10.

It is obvious that at lower stresses the difference of loading characteristics between glass granules and sand grains is less significant.

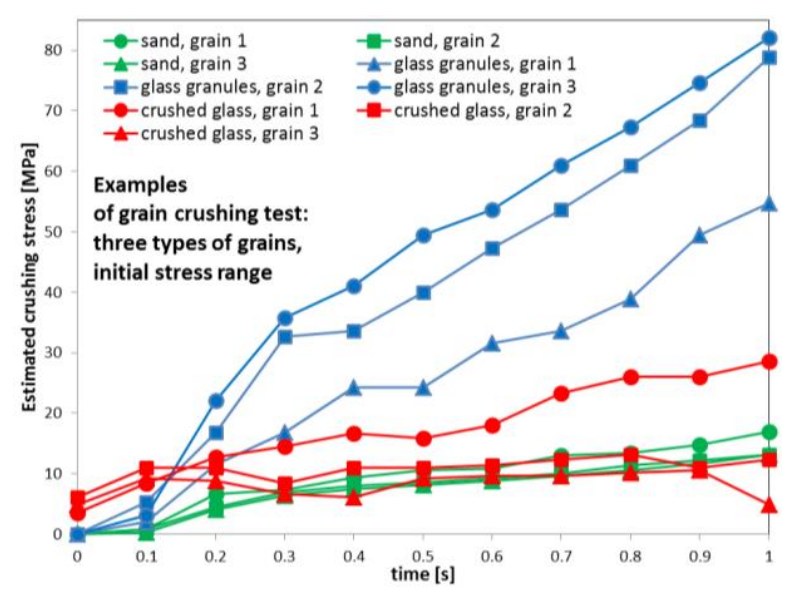

Fig. 10. 'Low stress' part of Fig.9.

The important finding is that they are both approximately linear, however with evident statistical spread. Closer examination of 'lower stress' response of crushed glass grains reveals some peculiar feature: the red lines in Fig.10 do not start from zero stress. It is the result of local crushing of the grains' sharp edges, due to which it is very difficult to determine when the grain gains actual contact with moving piston of mini press. Relatively high stress appears instantaneously at sharp edges and falls down immediately after some sharp edges breaking.

The result is some smoothing of the grain-piston contact area and the delayed start of the proper grain loading. Further loading leads to grain splitting to finite stable pieces, keeping some residual strength (Fig.8).

\section{2 'Macro-scale' loading tests}

The test procedure described in section 3.2 was employed to deduce how loading characteristics of individual grains could affect the behaviour of large assembly of grains. Only the results for glass granules and crushed glass are presented, because, as it was shown above, sand can be well represented by glass granules within the practical stress range. The other reason is that sand could not be used in photo-elastic observations.

Most of the reported tests were carried out on glass granules to check the repeatability of the results. Only one test on crushed glass sample was performed for comparison as far. All samples were prepared in the same way and had approximately the same dimensions. Their estimated average void ratio was about 0.51 and volume fraction of 0.66 was obtained on the base of simple calculations of the mass of granular material used and the dimensions of the granular assembly.

The purpose of the analysis presented in this section was to check deformation characteristics of granular samples subjected to different external loading within the range $0-4 \mathrm{MPa}$. The samples were confined and loaded on top of the sample by the vertical load (Fig.6).

Vertical displacement of the sample surface was selected as a measure of deformation and was read out from calibrated digital images, with accuracy of $0.1 \mathrm{~mm}$. 


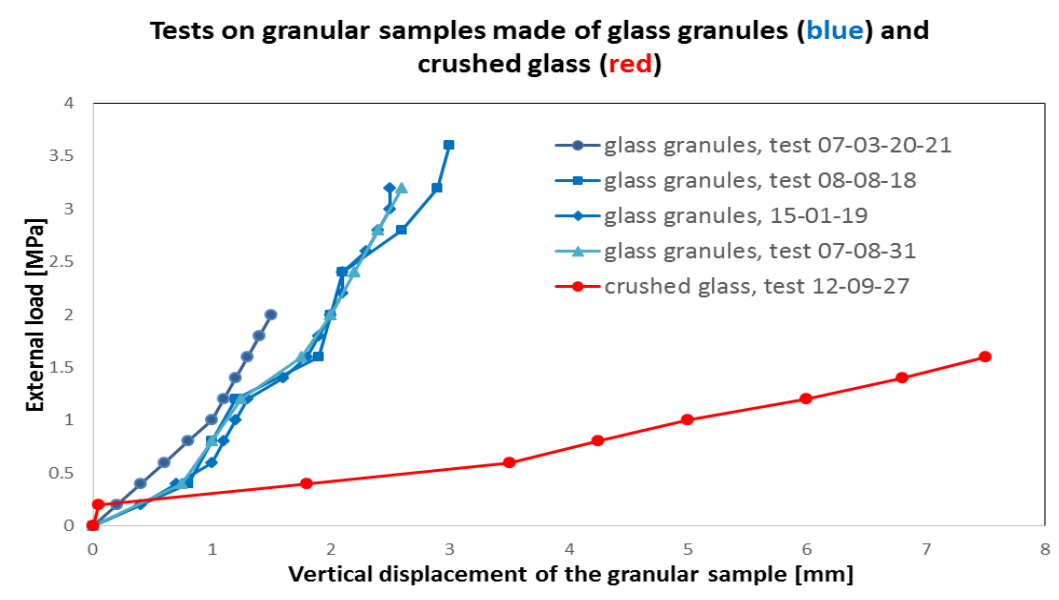

Fig. 11. 'Macro-scale' loading of granular sample: blue - tests on samples consisting of glass granules, red - test on a sample consisted of crushed glass grains.

Fig.11 presents the relationship between value of external load exerted on granular samples and their vertical displacements. Because all samples were of the same dimensions, the vertical displacement can be used as a valid measure for comparisons between different tests. It is also possible to replace displacements by vertical strains. The maximum value of vertical strain for tests represented in Fig.11 in case of crushed glass corresponds to vertical displacement $\sim 7.5 \mathrm{~mm}$ and equals $\sim 4.5 \%$, in case of glass granules vertical displacement $\sim 3 \mathrm{~mm}$ gives vertical strain $\sim 1.8 \%$. It can be seen from Fig.11 that all samples of glass granules, within the range of external stresses applied, give similar stressdeformation characteristics, regardless the maximum stress value. It is rather obvious taking into account that glass granules behave like elastic bodies up to a loading of some hundreds of MPa (Fig.9). It is quite reassuring to see from Fig.11 that with larger number of tests it would be possible to obtain common dependence between stress and strain, being a function of granular material micro-features - the individual grain characteristics. Deformation characteristics of macro sample of crushed glass differ visibly from glass granules behaviour. The dependence between stress level and displacement (or vertical strain) is also linear in case of crushed glass, but much more flat than in case of glass granules. As vertical displacements shown in Fig.11 must come from compaction, due to the imposed test conditions, one could say that crushed glass can serve best in research, where grain-scale brittle fracture plays an important role in controlling the compaction behaviour [6]. Due to that, any theoretical model of compaction phenomenon, to be verified on crushed glass, would require taking into account the complex behaviour of crushed glass grains under stress, including not only brittle fracture phenomenon in bulk grain volume (grain splitting), which seems to be secondary mechanism, but also some surface phenomena related to grain smoothing (local damage of sharp grain's edges). To study mechanisms of load transfer through granular materials, glass granules seem to be much better choice, as they are behaving linearly elastic and are practically indestructible within the range of practical stress levels.

\section{Conclusions}

As a result of research presented in this paper, one general conclusion can be drawn - the mechanisms of individual grain damage can strongly determine the suitability of different granular materials to be used in practice or in research. More detailed conclusions are as follows:

- within the range of practical stresses glass granules substitute well quartz sand - both have similar monotonic stress-deformation characteristics in similar stress and deformation range,

- crushed glass is difficult to control within low stress range of a few MPa due to unstable grain contacts at sharp edges - because of that crushed glass grains can be treated neither rigid nor soft,

- glass granules are better suited to analyse load transmission within granular materials, while crushed glass for modelling compaction related to brittle failure.

\section{References}

1. P. Dantu, Proc. 4th Int. Conf. on SMFEngineering, Butterworths, London, 1, 144-148 (1957)

2. T. Wakabayashi, Proc. 7th National Conference on Applied Mechanics, Japan, 153-158 (1957)

3. A. Drescher, G. De Josselin de Jong, J. Mech. Phys. Solids 20, 337-351 (1972)

4. D. Leśniewska D, Muir Wood, J. Eng Mech 135, 1038-1054 (2009)

5. D. Muir Wood, D. Leśniewska D, Granul Matt 13, 395-415 (2011)

6. R.H. Brzesowsky, C.J. Spiers, C.J. Peach, S.J.T. Hangx, J. Geophysical Research, 116, B06205, doi:10.1029/2010JB008120 (2011)

\footnotetext{
* Corresponding author: danuta.lesniewska@ibwpan.gda.pl
} 